\title{
Pantomime auf einem Blatt Papier Zu den Selbstbildnissen von Egon Schiele
}

'Choreographisches Gedicht ${ }^{1}$ entwickelte sich zu Beginn des 20. Jahrhunderts zu einer Denkfigur, die die Besonderheiten des freien Ausdruckstanzes, einer relativ junger Form der Künste, beschrieb, die nicht nur die Wahrnehmungsweisen, sondern auch die ästhetischen Bedürfnisse der Produzenten und Rezipienten veränderte. Die neue Art der Bewegungskunst markierte in der Epochenwende einen Paradigmenwechsel vom klassischen Ballett zur individuellen künstlerischen Darstellung, die allerdings ein komplexes kulturelles System war - es vereinigte sowohl alle Komponenten klassischer Bildung als auch den rhetorischen Ausdruck von Affekten.

Es war auch ein neues Objekt des Interesses von Hugo von Hofmannsthal. Seine vielfältige rezeptive Auseinandersetzung ${ }^{2}$ mit dem Tanz seiner Zeit integrierte Hofmannsthal in parallell laufende Reflexionen über den schöpferischen Umgang mit der Sprache. Es führte ihn zur Erkenntnis, dass die sich aus dem mimisch-gestischen Potenzial des Menschen speisende Ausdrucksform, die neben der Sprache der Worte, der Farben und Töne existiert, einen "Text«, sprich eine dichterische Vision entstehen lässt, die vom Körper der Tänzer in den Raum geschrieben wird. Dabei misst Hofmannsthal sich selbst die Rolle eines Lesenden zu, der den Körper und seine Bewegungskunst zu entziffern sucht.

Dass der Tanz und die Pantomime sehr nahe verwandt sind, betont Hofmannsthal in seinem 1911 entstandenen Essay »Über die Pantomi-

1 Nachdem Friedrich Nietzsche den Tanz zum dynamischen Denkmodell und Ziel jeder philosophischen Tätigkeit erklärt hatte, beschäftigten sich auch zahlreiche Literaten im Rahmen von Sprach- und Kulturkritik damit, den Tanz als stummes, transitorische Bewegungskunst des menschlichen Körpers poetologisch auszuwerten. Vgl. Roger W. Müller Farguell, Tanz-Figuren. Zur metaphorischen Konstitution von Bewegung in Texten. Schiller, Kleist, Heine, Nietzsche. München 1995, S. 278. Auch in der "Geburt der Tragödie aus dem Geiste der Musik« äußert sich Nietzsche zum Ursprung von Tanz und Sprache.

2 Neben seiner praktischen Beschäftigung mit den Szenarien, setzte sich Hofmannsthal mit Auftritten hervorragender Tänzerpersönlichkeiten wie Ruth St. Denis, Vaslav Nijinsky, Grete Wiesenthal u.a. auseinander, über die er weiterhin in seinen theoretischen Uberlegungen reflektierte. 
me«, den er in Anlehnung an die gleichnamige Schrift von Lukian ausarbeitet: Danach sind die mimetische Darstellung und der amimetische Ausdruckstanz vom Pantomimischen und von rhythmischer Bewegung durchwirkt. Was aber in diesem Text hervorgehoben wird, ist vor allem die "reine Gebärde«, die den Kern der Pantomime bildet, und am besten das Innere des Individuums zu offenbaren vermag. Sie ist »in Wahrheit höchst persönlich«, und in ihr wird »das menschliche Ganze" erkennbar: ${ }^{3}$ "Das Schöpferische im Schauspieler: eine Gebärde, in der der Leib einen seiner tausend Bezüge zum All enthüllt. Eine solche Gebärde ist sogleich ewig. Eine Gestalt ist ein Block aus Gebärden, die dicht übereinander liegen. $\aleph^{4}$

Die "reine Gebärde" verwirklicht sich, laut Hofmannsthal, in einem religiös ${ }^{5}$ motivierten, ursprünglichen Tanz, der in seinem Kern aus einem zeremoniellen Akt entsteht: »Auf Zeremonie läuft alles hinaus«. ${ }^{6}$ Sie vermag » ein Verhältnis zu umgebenden Personen, gedrängter, und bedeutender als die Sprache es vermöchte, auszusprechen, etwas an den Tag zu geben, was zu groß, zu allgemein, zu nahe ist, um in Worte gefaßt zu werden «? Hier artikuliert Hofmannsthal sein Erfahrungswissen in Fragen nach dem Schöpferischen des Körpers im Tanz, sowie nach der Inspirationsquelle. So benötigt der Tänzer nicht nur eine entsprechende körperliche Eignung, sondern auch ein spezielles, kulturelles Wissen - memoria -, auf Grund dessen er eine gemeinmenschliche Gebärde, wie ein für alle verständliches Symbol konstruiert. Seine Wirkung wird weiterhin in der Selbstvergessenheit des Körpers im Tanz intuitiv-individuell vervollständigt.

Das neue Tanzmodell eroberte nicht nur die Aufmerksamkeit solcher dichterischen Größen wie Hugo von Hofmannsthal, Ludwig Hevesi oder des Kulturkritikers Hermann Bahr, es galt auch als Inspirationsquelle für die historische Avantgarde in der bildenden Kunst und Literatur.

Solch ein "choreographisches Gedicht« wählt der bedeutendste Vertreter der Wiener Jahrhundertwende, Egon Schiele (1890-1918) zu seinem

GW RA I, S. 504f.

4 GW RA III, S. 480.

5 "religiös« soll hier im weitesten Sinne verstanden werden: Alltägliche Gebärden oder Handlungen werden in ihrem verborgenen zeremoniellen Charakter erfasst und demgemäß allgemeingültig ausgeführt.

6 GW RA I, S. 503.

7 Ebd., S. 502. 
Hauptthema. Ins Zentrum dieser "Choreographien« rückt er seinen eigenen Körper, den er in fast manischer Weise ${ }^{8}$ gestaltet.

Wolfgang Georg Fischer nennt nicht zufällig ein Kapitel seines SchieleBuches $^{9} "$ Die Pantomime des Ichs«, in dem er das mehrfache Deklinieren des Künstler-Ichs in seinen Selbstbildnissen verdeutlicht: "Er [Schiele] genießt die Doppelrolle von Modell und Maler, Schauspieler und Regisseur, mit einem Wort seine unzähligen selbstinszenierten Ich-Visionen machen das Kapitel Selbstporträt zum faszinierendsten in seinem Werk. ${ }^{10}$ Einerseits bezieht sich der Titel des Kapitels auf die Aussage von Schiele: "Ich bin alles zugleich, aber niemals werde ich alles zur gleichen Zeit tun «, ${ }^{11}$ die seine Neigung zum inneren Pluralismus bestätigt. Andererseits betont Fischer Schieles Vorliebe, in unterschiedliche Rollen zu schlüpfen und sie auszuleben, gleichzeitig hebt er auch die zerstörte Einheit des Ichs, seine Depersonalisierung hervor. Der Bezug der Pantomime zu den Selbstbildnissen von Schiele wird in diesem Beitrag im direkten Sinne des Wortes übernommen, denn der performative Umgang des Künstlers mit dem eigenen Körper entspricht dem Wesen der Pantomime: Sie ist der Ausdruck "einer anderen Welt, in der das Wort nicht existiert, in der Geste und Haltung aus der Realität hervorgegangen, und in Kontakt mit ihr, die ureigene Sprache sind «, ${ }^{12}$ sie ist »die Kunst der Form", und das "Material, aus dem diese Form geschaffen wird, ist der menschliche Körper. «13

\section{Besonderheiten der Selbstbildnisse von Egon Schiele}

Gewählt werden sechs Selbstbildnisse, die zwischen 1911 und 1917 entstanden sind: "Der Tänzer« (Selbstbildnis 1911, Abb. 1), "Prediger« (Selbstbildnis 1913, Abb. 2), "Kämpfer« (Selbstbildnis 1913, Abb. 3), "Sitzender männlicher Akt» (Selbstbildnis 1917, Abb. 4), "Männlicher

\footnotetext{
8 »Bis zu seinem 28. Lebensjahr hat er rund hundert Selbstporträts geschaffen, Rembrandt bis zu diesem Alter nur rund fünfzig." Wolfgang Georg Fischer, Egon Schiele 18901918. Pantomimen der Lust. Visionen der Sterblichkeit. Köln 1998, S. 147.

9 Ebd.

10 Ebd.

11 Briefe und Prosa von Egon Schiele. Hg. von Arthur Roessler. Wien 1921, S. 19.

12 Hans Bollmann, Untersuchungen zur Kunstgattung Pantomime. Hamburg 1968, S. 40.

13 Karl Günter Simon, Pantomime. Ursprung, Wesen, Möglichkeiten. München 1960, S. 72 .
} 


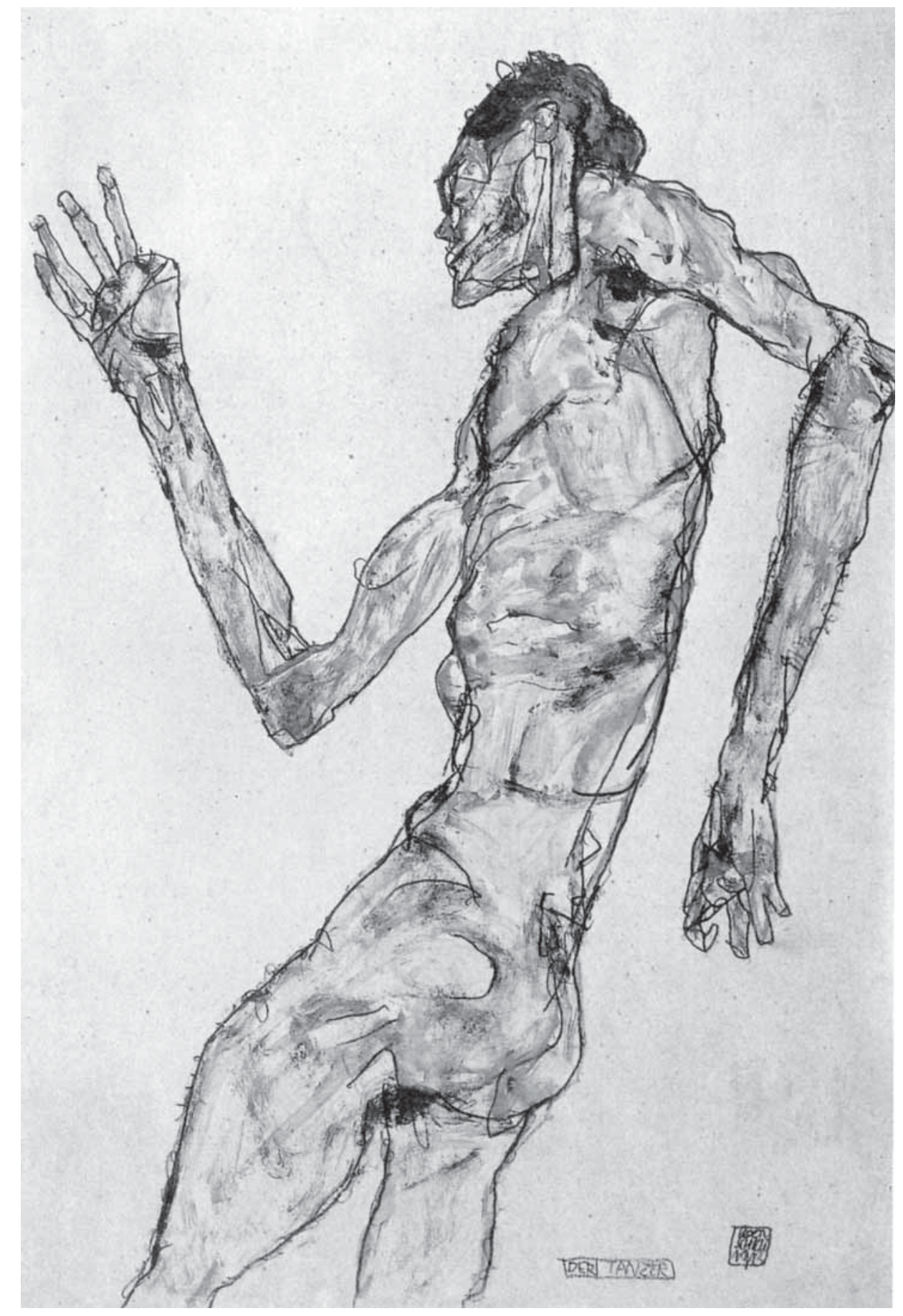

Abb. 1 


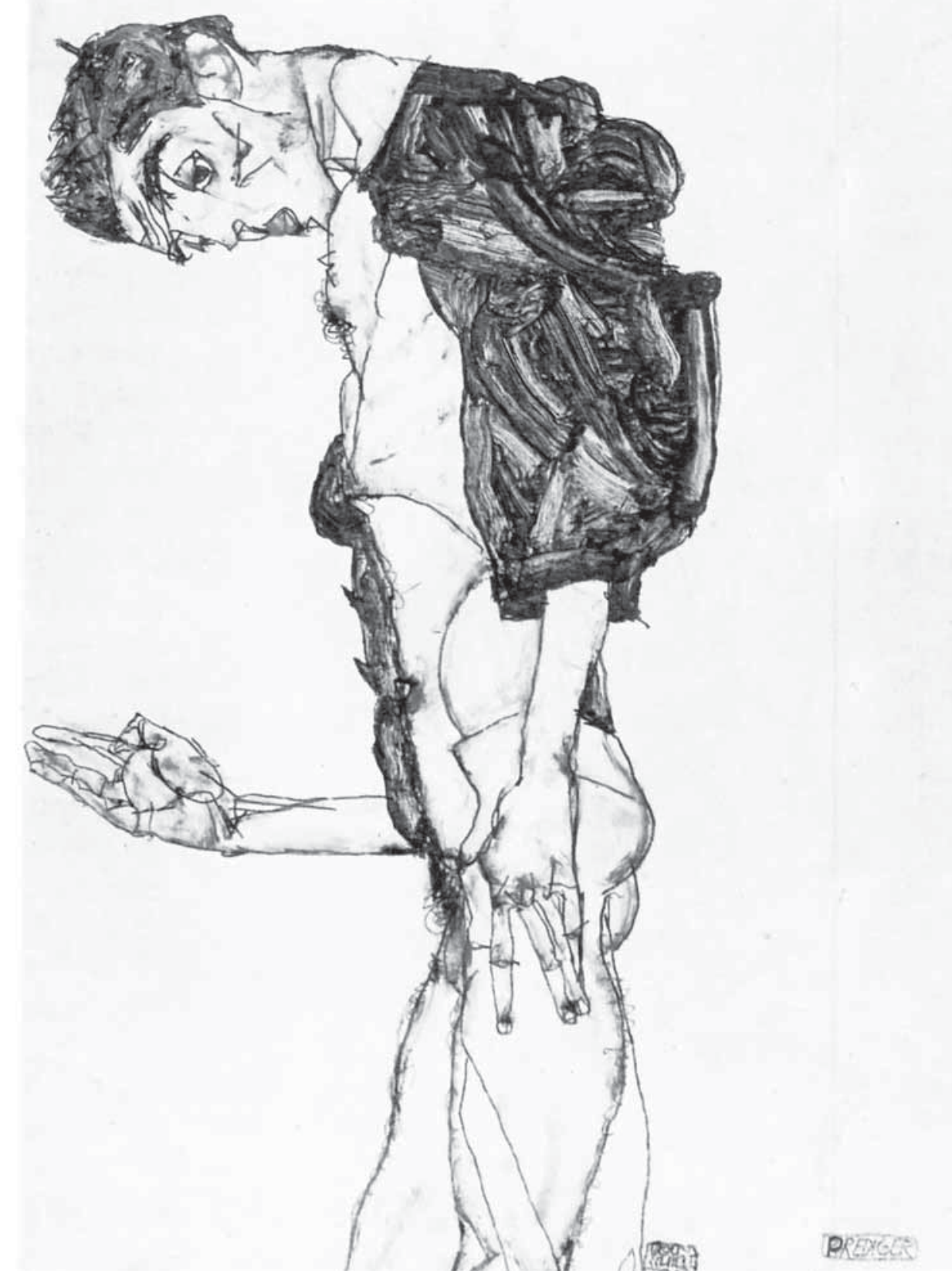

Abb. 2

Zu den Selbstbildnissen von Egon Schiele 371 


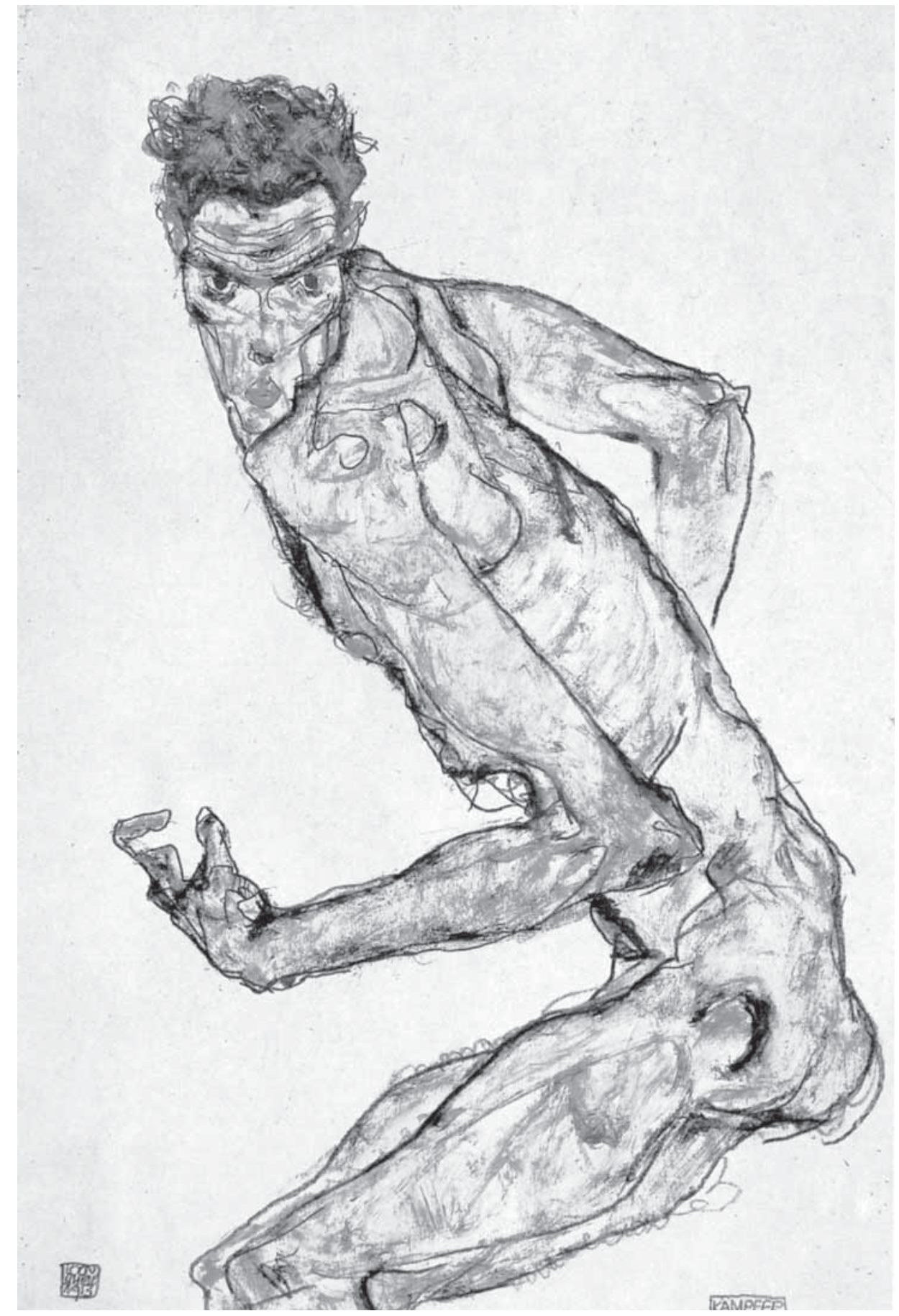

Abb. 3 


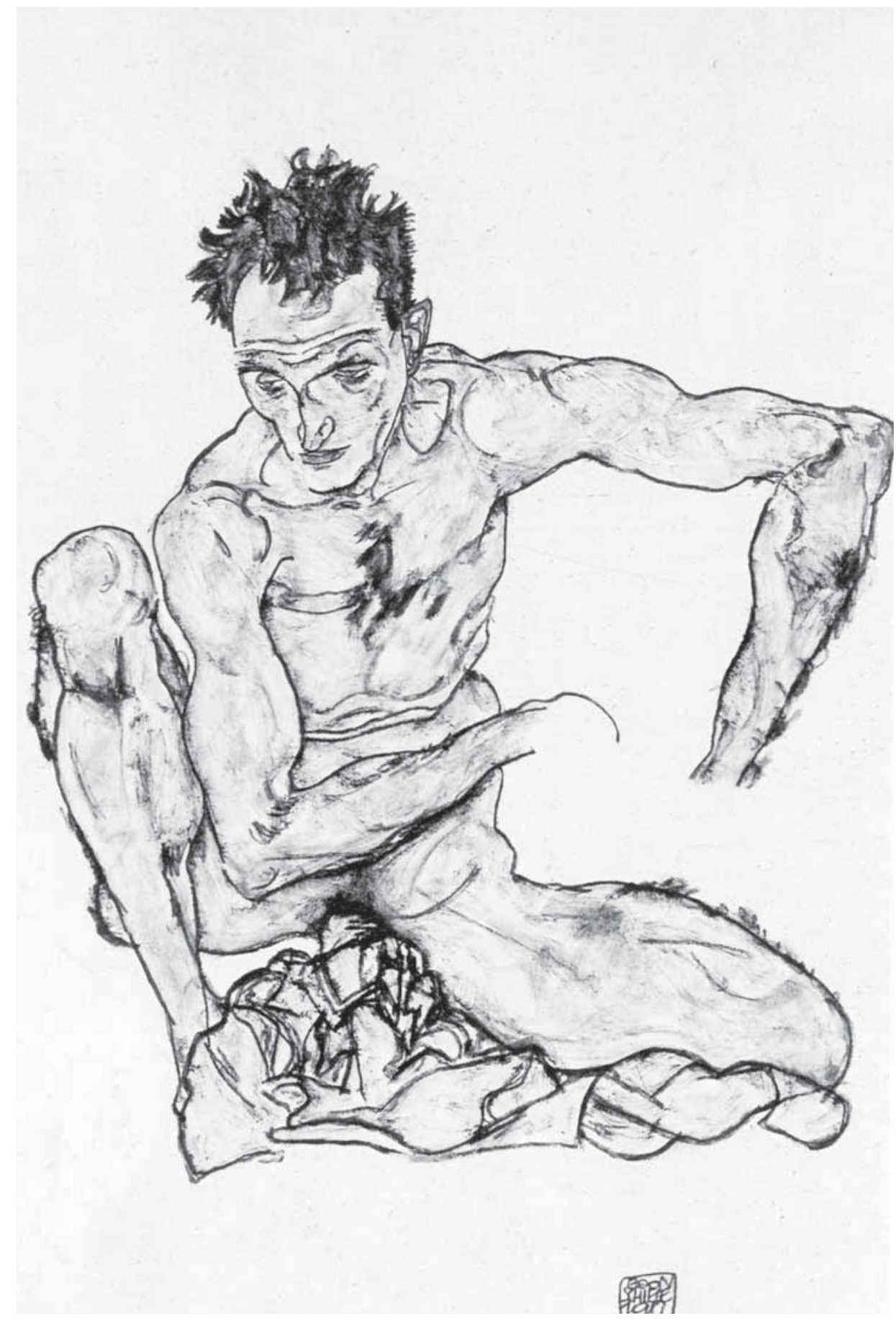

Abb. 4 


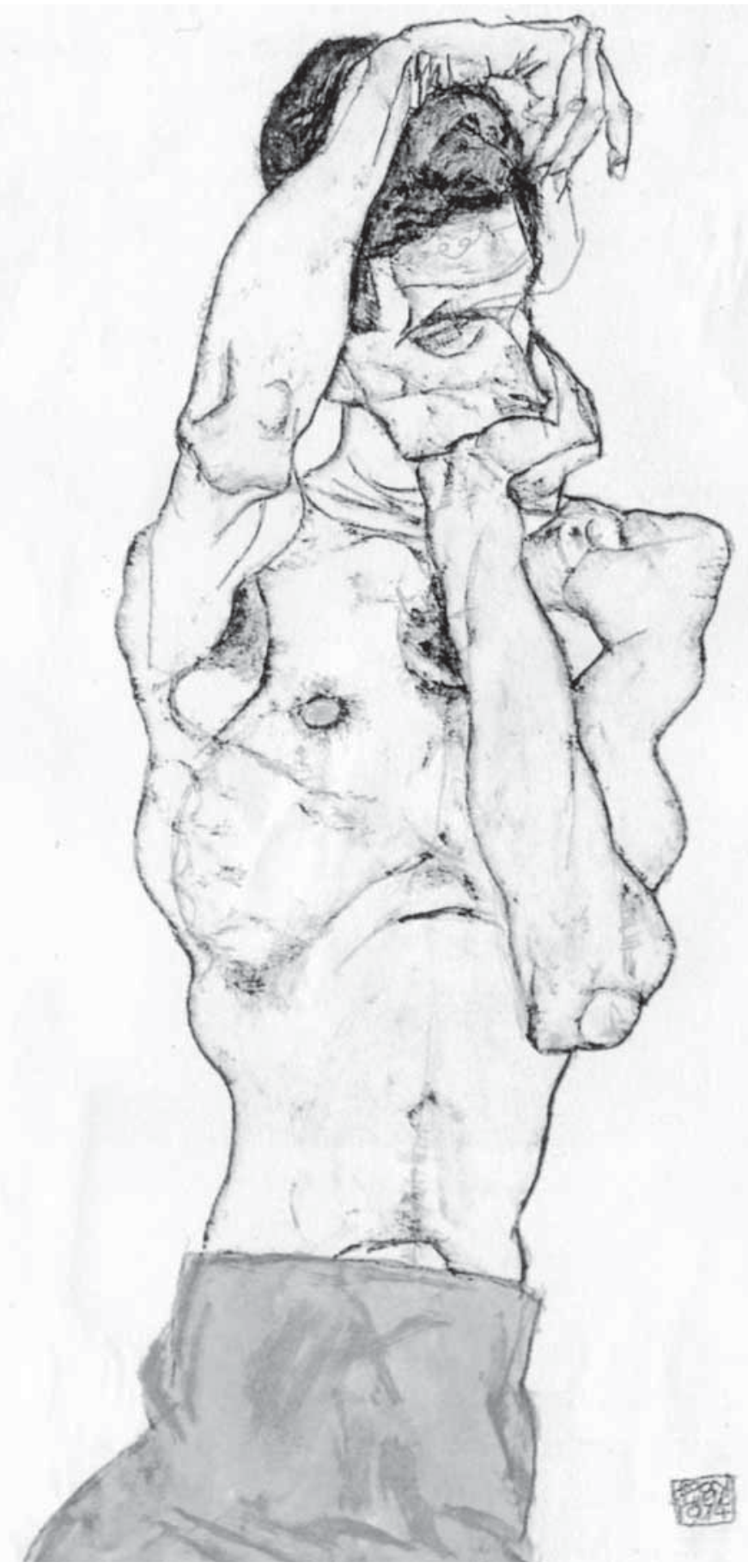

Abb. 5

374 Dalia Klippenstein 


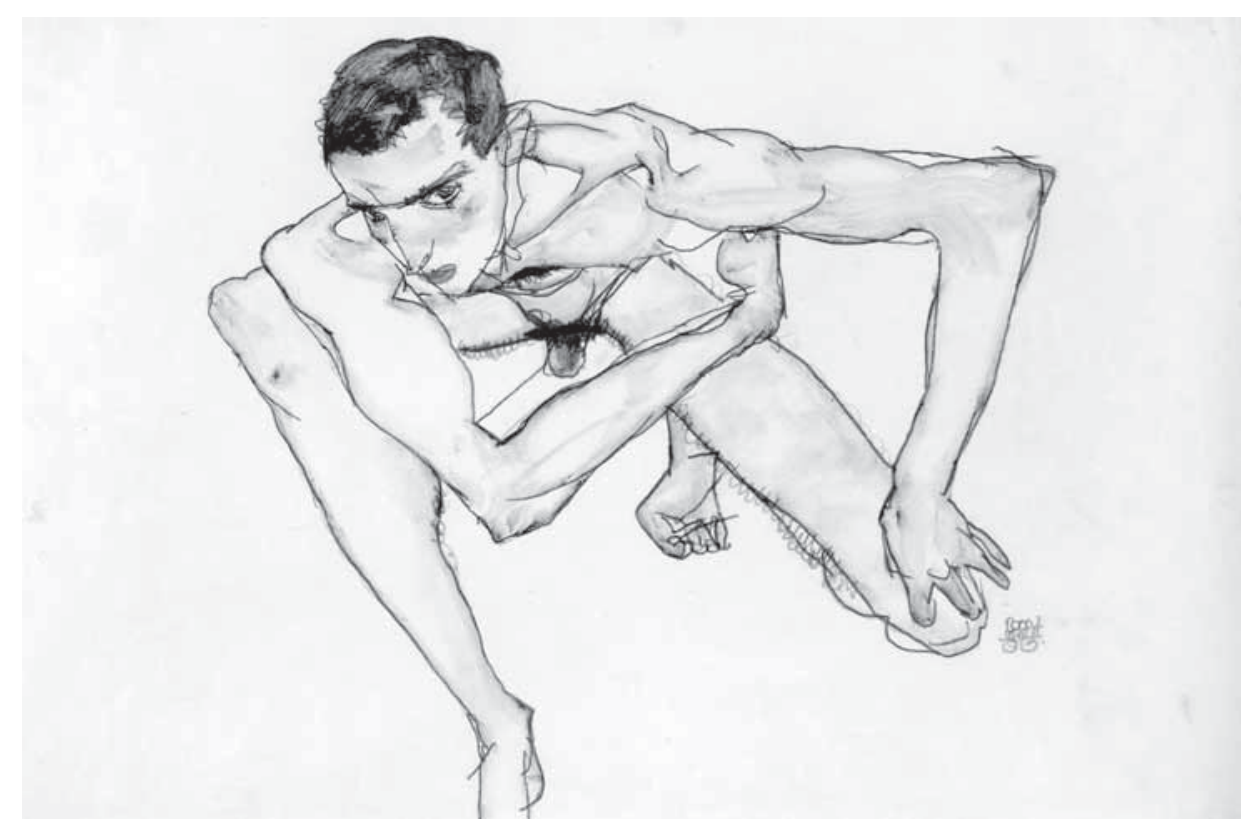

Abb. 6

Halbakt mit rotem Tuch" (Selbstbildnis 1914, Abb. 5), "Selbstbildnis in kriechender Stellung" (1913, Abb. 6). Es ist offensichtlich, dass es Schiele auf gar keinen Fall um die Anonymisierung seines Selbsts geht. Ganz im Gegenteil akzentuiert er die Kenntlichmachung seiner Person und Physiognomie. Der an den Arbeiten ablesbare Zustand seiner körperlichen Konstitution spiegelt seine starke Unterernährung wider, die sich an seinem ganzen Leib äußert: an den gelängten Gliedmaßen und Fingern, mit denen er unterschiedliche figurative Konstellationen bildete, deren symbolische Bedeutung nur ihm allein bekannt war. Arthur Roessler, sein Entdecker, Förderer und Biograph, verdeutlicht es in der Beschreibung seiner ersten Begegnung mit dem Künstler:

Empfindsamen Menschen mochte Schiele wie ein Sendling aus unbekannten Fernen anmuten, wie einer, der von den Toten auferstand und nun, voll einer schmerzlichen Verwirrung, eine geheimnisvolle Botschaft mit sich unter die Menschen trägt, ohne die rechte Gelegenheit zu finden, die Botschaft auszurichten. Sogar im Kreise berühmter Männer von bedeutendem Aussehen fiel Schiele als ungewöhnliche Erscheinung auf, wie ich später mehrmals beobachten konnte. Von hoher, schlanker, geschmeidiger Gestalt, mit schmalen Schultern, langen Armen und langgefingerten, knöchernen Händen, einem von langsträhnigem, wildzausigem, dunklem Haar umrahmten bartlosen 
und sonnverbrannten Antlitz mit breiter, querfaltig gefurchter, kantiger Stirn, einem Antlitz, dessen plastische Gesichtszüge meistens einen ernsten, fast traurigen Ausdruck trugen, wie von Schmerzen, die nach innen weinen, mit großen und dunklen Augen, aus welchen er, angeredet, gleichsam immer erst einen Traum scheuchen mußte, trat er einem frappierend entgegen. ${ }^{14}$

Die erwähnten Selbstbildnisse kennzeichnen sich durch spezifische Gemeinsamkeiten, die die Selbstdarstellungen wie Kettenglieder miteinander verbinden. Eines dieser Glieder wird bewusst oder eher unbewusst von Schiele in seinen Tagebüchern erwähnt: »Die Figur ist doch das Wesentliche, was mich am meisten erfüllt, der menschliche Körper.«15 »Ich glaube immer, daß die größten Maler Figuren malten «16, schrieb Schiele an seinen Onkel, Leopold Czihaczek. In diesen Aussagen verwendet der Künstler den Betriff `Figur in einem eingeschränkten Sinne und reduziert sie auf die äußere Gestalt des Körpers. Der ’Figur«-Begriff umfasst allerdings nahezu alle Bereiche der Künste und Darstellungstheorien:

[...] über die Bedeutung des plastischen Gebildes hinaus wird ’figurar zur Bezeichnung von Kontur - Zeichnung und Bild - und findet eine differenzierte Verwendung in den Darstellungsbereichen von Rhetorik, Grammatik, Logik, Mathematik, Musik, Theater und Choreographie. ${ }^{17}$

Abgeleitet von >fingere steht 'Figur vielmehr für den Aspekt der Beweglichkeit: Damit wurde immer schon "etwas Lebend-Bewegtes, Unvollendetes, Spielendes« bezeichnet. Seit der Antike transportiert der Begriff nicht nur die Vorstellung von einer (plastischen) Gestalt, sondern auch seine eigene Plastizität - jene performative Dimension, die die Figur selbst als eine Szene der Verwandlung erscheinen lässt. ${ }^{18}$ Zusammengefasst findet sich in den Selbstbildnissen von Schiele jene Ausfaltung

14 Arthur Roessler, Erinnerungen an Egon Schiele (erweit. Neuausgabe). Wien 1948, S. 5-7.

15 Zit. n. Tobias Natter, Das Tagebuch der Silvia Koller. Anmerkungen zu seiner Bedeutung für die Schiele Forschung. In: Broncia Koller Pinel. Eine Malerin im Glanz der Jahrhundertwende (Ausstellungskatalog). Jüdisches Museum Wien 1993, S. 95-110.

16 Brief von Egon Schiele an Leopold Czihaczek, 1. September 1911. In: Christian M. Nebehay, Egon Schiele. Leben und Werk in Dokumenten und Bildern. München 1980, S. 102.

17 Gabriele Brandstetter/Sibylle Peters, Einleitung. Figura I: Aufriß der Szene. In: Dies. (Hg.), De figura. Rhetorik, Bewegung, Gestalt. München 2002, S. 9.

18 Ebd., S. 8. Im Hinblick auf die begriffsgeschichtliche Untersuchung von Erich Auerbach bieten Brandstetter/Peters in ihrer Einleitung eine übersichtliche Zusammenfassung der Entwicklung und der Bedeutungsbandbreite des Figur-Begriffs an. 
von 'Figur', die die im Bilde fixierte Gestalt, den Rückgriff auf eine theaterspezifische Verwendungsweise und die Idee einer "Figur als offener Schauplatz« behandelt.

Weiterhin ist der monologische Charakter der Arbeiten auffällig. Die Figuren sind in ein enges Bildformat eingezwängt und in keinen visuell vorgegebenen Kontext eingebunden. Sie befinden sich entweder in Bewegung oder in einer ausdrucksvollen Haltung, oder beim Vollziehen einer bestimmten Gestik, sie leben aus ihrer Geste, sie agieren wie Darsteller in einem Spiel und verkörpern verschiedene Gestalten.

Die Figuren sind durch einen ausgesprochenen Stilisierungswillen des Leibes geprägt. Die wichtigste Konstante auf der eidetischen Ebene ist der hohe Grad asketischer Verhärmung. Es spiegelt sich durch die deutlich hervortretenden Beckenschaufeln, den Brustkorb, die Scharfkantigkeit der Knie und Ellenbogen. Dazu gehört auch die manieristische, hyperthrophierte Überlängung der Gliedmaßen und des Rumpfes, der spitzwinkelige Gesichtsumriss, die Geometrisierung der körperlichen Form, die graphisch bestimmte Silhouette. Zwischen 1911 und 1913 vollzieht sich ein Wandel in der zeichnerischen Manier Schieles. Das geübte Auge verliert die zarte Konturlinie und entdeckt ein nervöses, vibrierendes Lineament, eine Verhärtung der rissartigen Linienkontinuität, die durch kleine Querstriche und Spiralmotive bereichert wird.

Die chromatische Ebene enthüllt eine besondere Vorliebe des Künstlers für textile Stofflichkeit, die er auch auf der Haut seiner Selbst-Figuren entwickelt. Sie erscheint beinahe wie eine ornamental wirkende Oberfläche. Der Stil des Farbauftrags zeigt Schieles individuelle Malweise, sie dient keiner nachahmenden Malerei oder der natürlichen Erscheinung des Leibes, sie bricht auch mit der Tradition des Klimt'schen Ästhetizismus. Mit lasierend eingesetzten Malmitteln verleiht der Künstler den Figuren eine Transparenz und zugleich eine flache Körperstruktur, die jegliches Eindringen hinter die Fassade verweigert. Zu der expressivsten Sprache Schieles gehört die Darstellung des Hautgewebes. Durch eine außergewöhnliche Farbwahl - rote, grüne, braune Tupfen - wird die Haut dramatisiert. Die Tupfen verwandeln die Oberfläche des Körpers in einen Ort tragischer Erlebnisse, der Folterung, indem sie Schwären, Wunden, Geschwüre und Ekzeme assoziieren lassen. Die Hautfarbe erscheint mal anämisch, mal gelblich oder bläulich, was die Vorstellung 
eines kranken Körpers, einer Verwesung hervorruft. Durch die Maltechnik stilisierte Verletzungen Schieles verwandeln die Haut in einen Schauplatz des Schmerzhaften, des Morbiden, sogar der Kultivierung von Aggressionsausbrüchen:

Die Haut ist Blickfang, der Blick geht nicht durch sie hindurch, was hinter der Haut passiert, muss vorgestellt werden. Die an der Oberfläche sichtbaren und fühlbaren Veränderungen werden zum Anhaltspunkt für Vorstellungen über das, was im Inneren geschieht. ${ }^{19}$

Aufgrund der eidetischen und chromatischen Gemeinsamkeiten könnte die Auswahl von Schieles Selbstbildnissen durch eine Reihe weiterer Werke fortgesetzt werden: "Kniender männlicher Akt mit erhobenen Händen« (Selbstbildnis 1910), "Selbstbildnis im Hemd« (1910), "Selbstbildnis in kriechender Stellung" (1913), "Selbstbildnis mit erhobenem rechten Ellbogen« (1914), "Selbstbildnis als Akt, hockend« (1916) u.a.

Die im Bildraum taumelnde Figur »des Tänzers« hat eine direkte Verbindung mit einer szenischen Aufführung. Der sich vom Betrachter wegwendende Körper ist perfekt mit dem verschwindenden Profil kombiniert. Zur Beweglichkeit der Figur tragen ebenso die Position der Arme und die schräge Körperhaltung im Raum bei. Schon auf den ersten oberflächlichen Blick wird deutlich, dass das Charakteristikum dieser Figur nicht in erster Linie im Medium des Tanzes liegt, wie man es typischerweise wahrnimmt. "Der Tänzer« befindet sich im Fluss einer Bewegung, die im nächsten Moment in eine bestimmte Richtung weitergehen muss. Das Medium der Malerei hält diese Bewegung gebannt, es fragmentiert sie und irritiert den Betrachter: Das Bewegungsvokabular "des Tänzers" ist von der Anmut, Eleganz und Leichtigkeit des klassischen Tanzes weit entfernt. Schieles Konzentration fällt eher auf einen Ausdrucksgehalt, der aus dem pantomimischen Bereich stammt. Diese Komposition zeigt eine freie schöpferische Handlung, die vermuten, erahnen lässt. Karl Günter Simon nennt derartige Gebärden "abstrakt « oder "sinnleer «. ${ }^{20}$ Sie sind nicht wirklich abstrakt, sie bieten dem Zuschauer nicht sofort eine Assoziation zu einem konkreten Bezug an.

19 Karl-Josef Pazzini, Haut. Berührungssehnsucht und Juckreiz. In: Körperteile. Eine kulturelle Anatomie. Hg. von Claudia Benthien und Christoph Wulf. Reinbek bei Hamburg 2001, S. 157.

20 Simon, Pantomime (wie Anm. 13), S. 89. 
Ein gesteigertes Interesse am Tanz zeigt Schiele auch in den anderen Arbeiten: "Die Tänzerin« (1913), »Friederike Maria Beer« (1914) oder »Tänzerin Moa" (1911) u.a.

Was für Schiele bei der Darstellung seiner Figuren typisch ist, ist die Erscheinung der Gewaltsamkeit. Im Selbstbildnis "Sitzender männlicher Akt« stellt sich Schiele in sitzender Stellung dar. Das rechte Bein ist angewinkelt und das Knie zum Körper angezogen. Das linke Bein hat eine merkwürdig deformierte Form, die sich schwer beschreiben lässt. Es scheint angewinkelt zu sein, das Knie liegt auf dem Boden. Der restliche Teil des Beins sowie der Fuß ist nicht zu sehen. Die Hände beider Arme sind kaltblütig "amputiert«. Die Darstellung verwandelt Schieles Selbst in einen Krüppel, in ein Opfer, und zeigt seine Neigung zur Selbstverstümmelung. Der Ausdruck einer derartigen Gewaltsamkeit findet seinen Widerhall in der Aussage von H. Holland über die Figuren von H. Marée: es gäbe für solche Figuren in keiner orthopädischen Anstalt Heil und Genesung. ${ }^{21}$

Auch die von Schiele vollzogenen Mutationen seiner Figuren schreiben sich in den Kontext der Gewaltsamkeit ein. Die im "Selbstbildnis in kriechender Stellung« übermäßig ausgedehnten Gliedmaßen in Kombination mit deren Konstellation lassen die Gestalt insektenhaft wirken. Das Bildnis entfernt sich von der Wiedergabe eines menschlichen Wesens und wirkt vielmehr wie ein "Verwandter" von Gregor Samsa. Man könnte behaupten, dass Schiele vom expressionistischen Zeitgeist infiziert war, und dass seine Zelebrierung der Gewaltsamkeit, der Anomalie, des Krankhaften auf radikale Weise ein "singuläres" Dasein oder »anders-Sein« im qualitativen Sinne enthüllt. Es darf aber nicht außer Acht gelassen werden, dass im Zentrum der Pantomime des 19. Jahrhunderts in Frankreich nicht nur Komik und Amüsement stand. Sie war ein Spiel,

das um die bewegten Bilder von Gewalt, Mord und Totschlag, Verstümmelung, horribler Deformation, Unheimlichkeit und - nicht zu vergessen - gnadenloser Unmoral gravierte. [...] Ganz generell formuliert: Die brutale Szene ist in all ihren Variationsmöglichkeiten aus unserer Sicht der eigentliche, im

21 Zit.n. Max Imdahl: Vier Aspekte zum Problem der ästhetischen Grenzüberschreitung in der bildenden Kunst. In: Die nicht mehr schönen Künste. Grenzphänomene des Ästhetischen. Poetik und Hermeneutik. Hg. von Hans R. Jauß. München 1968, S. 496. 
Laufe der modernistischen Evolution des Genres intensiver reflektierte und erschlossene groteske Kern der Pantomime des 19. Jahrhunderts. ${ }^{22}$

$\mathrm{Zu}$ Schieles Vorlieben gehörte die Einführung unterschiedlicher Draperien oder Kleidungsstücke, die entweder eine neutrale Funktion erfüllen oder sie fügen spezifische symbolische Bedeutungen hinzu. Die Draperie, die unten zu den Füßen im "Sitzenden männlicher Akt« liegt, hat keine verschleiernde Funktion und erscheint bloß als stoffliches Detail, als Accessoire. Das Lendentuch im »Männlichen Halbakt mit rotem Lendentuch" verweist auf eine bekannte ikonographische Symbolik. Es wurde von Schiele offensichtlich aus dem Repertoire der Heiligenfiguren entnommen: Jesus Christ, der hl. Antonius oder der hl. Sebastian ${ }^{23}$ werden meistens mit einem weißen Lendentuch versehen. Durch solch ein Detail stilisiert sich Schiele zum Künstlerheros, der in sich das Leiden mit der Schöpfungskraft verbindet. ${ }^{24}$

Die Arme und Hände der Figur haben eine "sprechende« Funktion und dienen zur Kodierung einer weiteren bekannten Ikonographie. Der rechte Arm ist so erhoben, dass er den Kopf umklammert. Mit dem linken Arm wird der Kopf abgestützt, das Kinn und die ganze Mundpartie bleiben mit der Hand bedeckt. Die Verflechtung dreier Körperteile (Kopf und beide Arme) zeigt Schieles Rückgriff auf das kulturelle »Bildgedächtnis«, auf die Überlieferung des Melancholikergestus.

Schiele verleiht den meisten Selbstbildnissen die neutrale Bezeichnung "Selbstbildnis" und bindet sie somit in keinen erzählenden Inhalt ein. Anderen gibt er überraschenderweise konkrete Rollenzuschreibungen: der Tänzer, Kämpfer, Prediger. Ein vom Künstler verliehener Titel gilt bekanntlich als eine äußerst wirksame Referenz, er trägt Signalcharakter.

22 Jörg von Brincken, Tours de force - Die Ästhetik des Grotesken in der französischen Pantomime des 19. Jahrhunderts. Tübingen 2006, S. 3.

231914 fertigte Schiele ein Ausstellungsplakat für die Galerie Arnot. Auf dem Plakat ist sein Selbstbildnis als hl. Sebastian zu sehen, der von Pfeilen durchbohrt ist. Allerdings führt Schiele in die Ikonographie der Heiligenfigur einen roten Mantel ein und verändert so die traditionelle Darstellung.

24 Viele AutorInnen betonen in ihren Forschungen, dass sich Schieles Selbstdarstellungen (asketischer Körperbau, märtyrerhafte Züge in Kombination mit Details aus dem sakralen Bereich) in eine Tradition des 19. Jahrhunderts einreihen, die im Künstler einen Propheten oder Heiligen sah. Agnes Husslein-Arco/Alfred Weidinger, Egon Schiele - Selbstporträts. Vom ewigen Träumen voll süßestem Lebensüberschuss. In: Egon Schiele. Selbstporträts und Porträts. Hg. von Ders. und Jane Kallir. München, London, New York 2011, S. 25f.; Fischer, Egon Schiele 1890-1918 [wie Anm. 8], S. 157; Klaus Albrecht Schröder, Egon Schiele. Eros und Passion. München, New York 1998, S. 56 u.a. 
So wird der Betrachter zur assoziativen Bildlektüre aufgefordert, wird aber zugleich irritiert, denn die verbale Aussage ist im visuellen Ausdruck nicht deutlich erkennbar, sie ist eher interpretierbar und möglicherweise vom Künstler bewusst kodiert.

Mit der Figur des "Predigers«, die in Profilansicht mit gesenktem Kopf erscheint, widerspricht Schiele der typischen Position des Redners und Verkünders des Gottes Wortes. Die Haltung des Rumpfes wie auch der linke Arm sind unnatürlich in die Länge gedehnt. Der rechte Arm ist im Ellenbogen zum rechten Winkel so gebeugt, dass der waagerecht ausgestreckte Unterarm die Haltung des Kopfes aufnimmt. Seiner Darstellung des "Predigers« fügt Schiele eine Prise ungezügelter Dreistigkeit hinzu, indem er seine Figur nicht mit einem Talar oder einer Soutane versieht, sondern mit einem aufgeknöpften, knappen Hemd, das in so einem Kontext sehr provokativ wirkt. Noch provokativer erscheinen der entblößte Genitalbereich, die Andeutung der Brusthaare und das fehlende Beinkleid, die im »kirchlichen« Kontext die Wirkung des Obszönen verstärken. Es ist nicht leicht, die Pose der Figur einer "gestischen Grammatik « des »Predigers« zuzuordnen, denn sie ignoriert das Vorgegebene im Titel völlig. Somit verwirrt Schiele die Zeichen und unterbricht die intermediale Beziehung zwischen der verbalen Angabe und der visuellen Komposition. ${ }^{25}$

\section{Pantomimische Darstellung in den Selbstbildnissen von Egon Schiele}

Das zunehmende Interesse an der Pantomime förderte nicht nur die Popularität des freien Ausdruckstanzes, der sich pantomimischer Ausdrücke bediente und dadurch verblüffende visuelle Wirkungen erzeugte. Als selbstständige, von den anderen Künsten - Tanz, Akrobatik, Marionettentheater - unabhängige Kunstgattung, etablierte sich die Pantomime im Österreich des 19. Jahrhunderts unter dem großen Einfluss

25 Auch in den anderen wenigen Beispielen wird ein ähnlicher Umgang des Künstlers mit kodierten Botschaften in seinen Arbeiten verfolgt: "Rufer « (1913) zeigt sein nachdenkliches Gesicht und eine stumme Miene, die durch den betont geschlossenen Mund hervorgehoben wird; "Anarchist« (1909-1910) erscheint in völliger "grünlicher « Nacktheit, von der die Kopf- und Achselhaare sowie die Schampartie rot akzentuiert werden. Werden in Betracht die bekanntesten, jedes Tabu brechenden Akte von Schiele gezogen, wirkt die gemäßigte Präsentation der "Anarchie« überraschend neutral. 
Frankreichs. ${ }^{26} \mathrm{Zu}$ der Zeit konnten sich die Franzosen auf diesem Gebiet mit Namen schmücken, wie Jean Gaspard Debureau, Etienne Decroux, Copeau u.a. Eine besondere Rolle in der Geschichte der Pantomime spielte die Wiederentdeckung der Commedia dell'Arte und die Wiederbelebung der alten italienischen Zannifiguren. Angemerkt sei hier, dass der Erfolg des Stegreifspiels an der szenischen Wirkung, am Spektakulären, an allem, was optischen Anspruch hatte, lag. Die Commedia dell'Arte war ein Produzent reiner Bilder, daher sind als kulturhistorische Quellen zu diesem Theater nur noch Illustrationen und Bilder als Anschauungsmaterial überliefert. Die Begeisterung der Österreicher für diese Figuren spiegelt sich nicht nur in der buchstäblichen Übernahme der in Frankreich durchgeführten Synthese von italienischer und französischer Commedia wider, sondern auch in den literarischen Versuchen, Szenarien für ein Pantomimenspiel zu entwerfen: Richard BeerHofmann schreibt bereits 1892 in enger Zusammenarbeit mit Hugo von Hofmannsthal die Pantomime "Pierrot Hypnotiseur", Hofmannsthal selbst verfasste 1901 seine erste Pantomime »Der Schüler", und Arthur Schnitzlers Pantomime »Die Verwandlungen des Pierrot« entstand 1908. Schiele konnte über die neuesten Literatur- und Theaterareignisse in den Hietzinger Kaffeehäusern erfahren, in denen er und sein Gönner Arthur Roessler verkehrten. ${ }^{27} \mathrm{Ob}$ er ein enthusiastischer Besucher der Theater der Wiener Vorstädte war, in deren Repertoire pantomimische Aufführungen standen, bleibt eine offene Frage. Christian M. Nebehay verweist in seiner Schiele-Biographie darauf, dass der junge Künstler, der sich nach dem Tod seines Vaters in der Obhut seines Onkels, Leopold Czihaczek, befand, mehrmals das Burgtheater besuchte:

Die Kammermusikabende in seinem Heim (des Onkels) interessierten Egon ebensowenig wie die regelmäßigen Besuche des Burgtheaters. Anfangs mochte ihm das wohl Spaß gemacht haben, denn es scheint, dass er es glänzend verstand, Gesten und Sprache von Schauspielern nachzuahmen. Auch Heinrich Benesch berichtet darüber, dass Schiele seinen Akademie-Professor Griepenkerl großartig imitiert habe. ${ }^{28}$

26 Rainer Hank beleuchtet in seinem Text die wichtigsten Aspekte der Entwicklungsgeschichte von Pantomime im Österreich. Mortifikation und Beschwörung. Zur Veränderung ästhetischer Wahrnehmung in der Moderne am Beispiel des Frühwerkes Richard Beer-Hofmanns. Frankfurt a.M. 1984, S. 234-242.

27 Vgl. Nebehay, Egon Schiele (wie Anm. 16), S. 40 f.

28 Ebd., S. 39. 
Auch später, als Schiele 1912 bei der Familie Lederer in Ungarn zu Gast war, berichtete er Roessler in einem Brief: »Wir waren abends noch im Theater, welches das erste, älteste Ungarns sein soll; ich verstand nichts aber die Darsteller haben ganz eigenartige rassige Bewegungen [...]. $\ll^{29}$ Diese biographischen Momente zeigen einerseits Schieles Gleichgültigkeit der Theaterkunst gegenüber, andererseits richtete er sein Augenmerk auf die Gestik und Bewegungen, die er sich erfolgreich aneignen konnte.

Einen besonderen Einfluss auf den Künstler übte sein Freund Erwin Osen (1891-1970) aus, der sich selbst »Mime van Osen« nannte:

Hochgewachsen, schlank, hager wie ein Araber, mit dem blassen und bartlosem Gesicht eines 'gefallenen Engels`, in eleganter Kleidung und unaufdringlich, unprotzig, aber doch auffallend geschmückt mit einigen exotischen Fingerringen und ebensolcher Nadel in der hochbauschigen, buntschillernden Halsbinde, trat ihm der Abenteurer entgegen ... Überdies gesellte sich bei dem jungen Mann zu der augenscheinlich virtuosen mimischen Ausdrucksfähigkeit auch noch der nicht minder gewandte Wortausdruck der leicht spielenden Phantasie des geborenen Improvisators im Erfinden seltsamer Reiseerlebnisse. ${ }^{30}$

Osen war ein Künstler, der seinen Lebensunterhalt als Theatermaler verdiente, und allem voran verfügte er über eine virtuose Ausdrucksfähigkeit, die er durch Varietéauftritte zusammen mit seiner exotischen Freundin Moa unter Beweis stellte. Einige gestische Elemente, wie auch extatische Körperhaltungen oder eine übersteigerte Mimik wurden von Schiele seinem Freund entlehnt und in vielen Selbstbildnissen zitiert (Abb. 7). ${ }^{31}$

Die Ballettaufführungen der "Ballets Russes« von Serge Diaghilev und ganz besonders die Virtuosität des Fronttänzers Vaslav Nijinsky soll eine weitere Inspirationsquelle für den Künstler gewesen sein. Elisabeth von Samsonow, der das Archiv des Wien Museums zugänglich war,

29 Ebd., S. 146.

30 Roessler, Erinnerungen (wie Anm. 14), S. 37.

31 Nebehay, Egon Schiele (wie Anm. 16), S. 77-86. Katharina Sykora, Performative Selbstinszenierung und Geschlech-terirritation bei Egon Schiele. In: Egon Schiele. Inszenierung und Identität. Hg. von Pia Müller-Tamm. Köln 1995, S. 46f. Reinhard Steiner, Egon Schiele 1890-1918. Die Mitternachtsseele des Künstlers. Köln 1999, S. 44. Frank Whitford, Egon Schiele. München 1998, S. 69-73. Patrick Werkner, Schieles Körperposen und Aspekte ihrer Rezeption. In: Egon Schiele. Melancholie und Provokation. Hg. von Elisabeth und Diethard Leopold. Wien 2011, S. 74. 


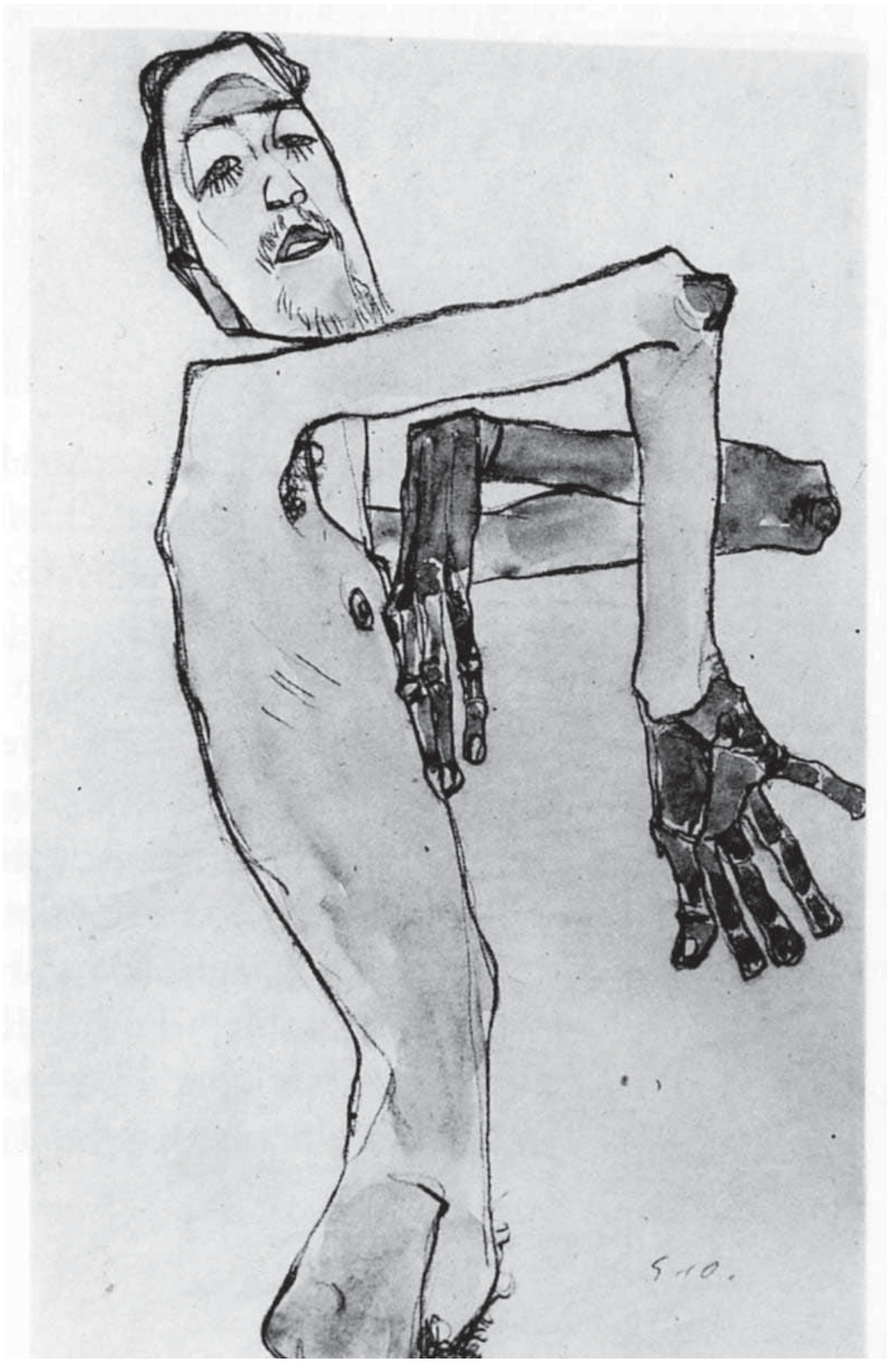

Abb. 7

384 Dalia Klippenstein 
hatte die Möglichkeit das "grüne Notizbuch" von Schiele und seinem Freund Anton Peschka zu analysieren. ${ }^{32}$ Es ist nicht klar, ob Schiele tatsächlich die Ballettaufführungen der Russen erlebt hat. Im "grünen Notizbuch « findet sich aber ein wirr verfasster kurzer Eintrag, der andeutet, dass das Ballett "Nachmittag eines Fauns" ("L'apres-midi d'un faune"), in dem Nijinsky als Choreograph debütierte, Schiele und Peschka nicht entgangen sein konnte:

[S]ie öffnete ihre Schenkel zwischen welche er sich legte und wie das leichte Wallen eines Schleiers der am Boden liegt und welchen Luftpolster bauschen so war die Bewegung seines Körpers als er an ihr klebte im heißen Kusse wie der Falter auf der Blume. [...] Er erinnerte sich dann einst im Walde in der Nacht so im nassen Grase gelegen zu sein am Bauche. Es blitzten ihm vorne am herunterhängenden Haar Wasserperlen wie einen Faun der im Regen tanzte und nun müde war. - die langen Bäume standen mit tiefblauvioletten Linien neben ihm wie jetzt der Wahnsinn seines Empfindens (Grünes Notizbuch Blatt 65 aus Teil II). ${ }^{33}$

Dieses Zitat aus dem Büchlein ist offensichtlich eine Anspielung auf die Neuinterpretierung der Schlussszene des Balletts, in der Nijinsky als Faun den von einer Nymphe hinterlassenen Schal liebkoste und dabei einen symbolischen Liebesakt inszenierte. Viel wichtiger erscheint die Tatsache, dass die Erneuerung des Bewegungsvokabulars durch Nijinsky überall als künstlerische Revolution avancierte. Als Ausgangspunkt für den jungen Choreographen diente ein gemeinsamer Besuch mit Léon Bakst im Louvre, wo dieser ihn auf die antike griechische Vasenmalerei aufmerksam machte. Die gesamte Choreographie war auf Zweidimensionalität angelegt. Alle Bewegungen wurden im Profil gezeigt. Die Tänzerinnen vermittelten den Eindruck griechischer Statuen in einem Fries, die Bewegungen des Fauns wirkten eckig-gehemmt, vereinfacht,

\footnotetext{
32 In ihrer Forschung berichtet von Samsonow von den Schwierigkeiten zu verstehen, wer im "grünen Notizbuch" die Eintragungen gemacht hat - Schiele oder Peschka: »Handschrift und Ausdrucksweise wirbelten [durcheinander]. Das Chaos in dem Büchlein ging so weit, dass derjenige bzw. diejenigen, die dieses Buch geführt hatten, in allerhöchster Beliebigkeit hineinschrieben und -zeichneten, sogar die Aufeinanderfolge der Seiten großzügig ignorierend. Der Duktus des Geschriebenen war bruchstückhaft, pathetisch, intim und zugleich wild auf den Seiten verteilt, obgleich sich sehen ließ, dass die Bindung des Büchleins nicht nachträglich war." Elisabeth von Samsonow, Egon Schiele: Ich bin die Vielen. Mit einem Nachwort von Peter Sloterdijk. Wien 2010, S. 122.

33 Ebd., S. 117f.
} 
kubistisch stilisiert. Dies war eine absolute Abkehr von den gewohnten klassischen Posen, Mimik und Figuren. ${ }^{34}$

Die Pantomime- oder Tanzaufführung lässt sich nur fragmentarisch wahrnehmen. Daran ist nicht nur das Augenblickliche der Aufführung schuld, sondern die Wahrnehmungsfähigkeit generell. Der Betrachter oder Zuschauer ist nur imstande, lediglich Ausschnitte, eben Fragmente des Geschehens, mit den Augen zu erfassen. So wird die Vollständigkeit der Darbietung erst durch eine Folge von »Schnappschüssen« hergestellt, die unser Blick aneinanderfügt.

Als besonders illustratives Beispiel dafür erscheinen die Photos der Pantomime von Marcel Marceau (»der gerichtshof«): Die Liveaufführung wird mit Hilfe von 21 Photosequenzen, die neben- und aneinander gereiht werden, rekonstruiert und als eine kontinuierliche Handlung vorgestellt (Abb. 8).
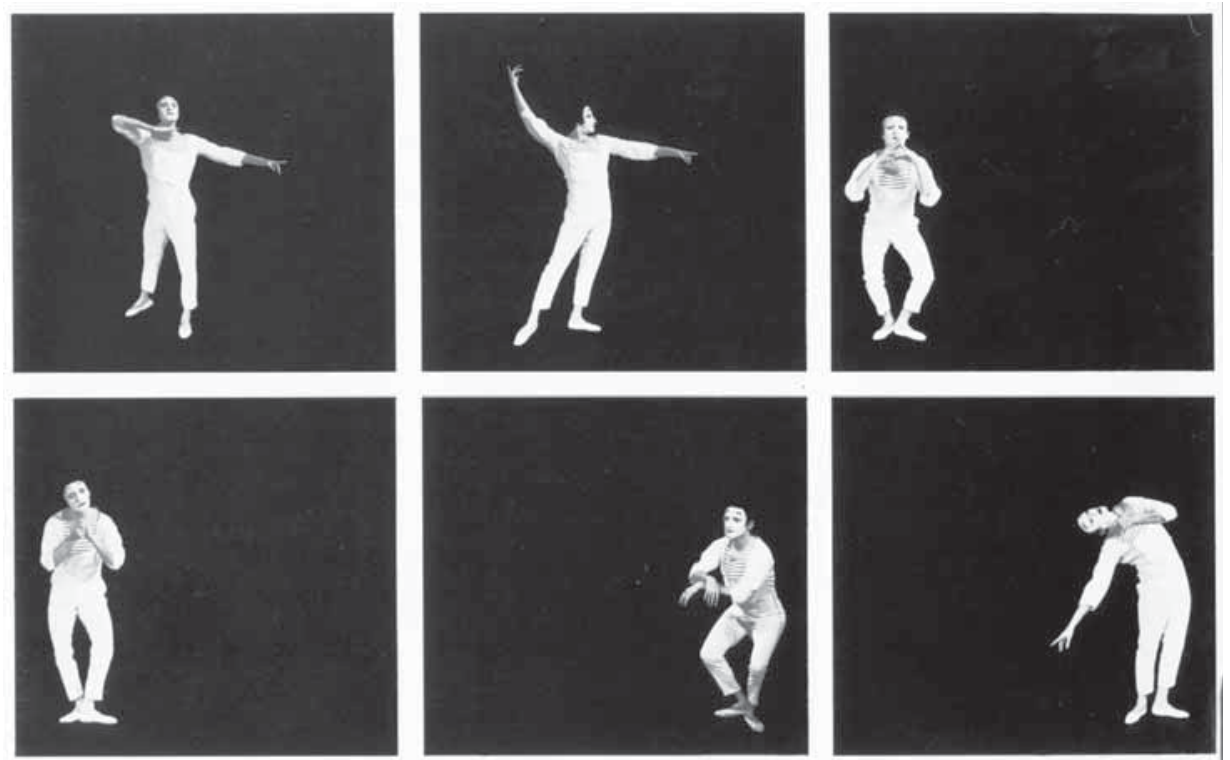

Abb. 8

34 Auch Hugo von Hofmannsthal schwärmt in seinem Text »Über die Pantomime« von Nijinskys außergewöhnlicher Choreographie. Laut ihm vermochte der Tänzer »in der Gebärde eines, der mit hohler Hand am Quell sich Wasser schöpft, alle Reinheit und Erhabenheit der unverderbten menschlichen Natur zu offenbaren." (GW RA I, S. 503) Wovon Hofmannstahl hier spricht, sind mimetische Gebärden, die in der rhythmischen Logik der Pantomime zu symbolischen Bewegungen werden, die in der Sprache nicht abzubilden sind. 
Betrachtet man alle sechs Bildnisse von Schiele auf einmal, so hat man den Eindruck, dass der Künstler seine Figuren in momentanen, für die Pantomime typischen Bewegungen und Haltungen festhält. Aufgrund der vorgestellten Gemeinsamkeiten auf der eidetischen und chromatischen Ebene kann der Blick des Betrachters ungestört einer Figur nach der anderen folgen und sie in einer Kontinuität verbinden. In der raschen Bildabfolge scheinen die voneinander unabhängig existierenden Figuren in einer Serie zu einem Objekt und zu einer pantomimischen Darstellung zu verschmelzen. Das heißt Schiele holt die Bewegungen in das Format der bildenden Kunst, in das statische Bild hinein und präsentiert jedes Selbstbildnis als stillgestelltes Fragment der Handlung oder als stillgestellte Filmsequenz: "Bild und Bewegung: das sind die gleichen Elemente, aus denen die Pantomime und der Stummfilm lebt.«35

Schieles Interesse am Effekt der gebannten Bewegung bzw. Handlung spiegelt sich auch in einigen Doppelselbstbildnissen wider. Auf der Zeichnung "Doppelselbstbildnis" sind zwei Schiele-Figuren in expressiven Posen zu sehen (Abb. 9). Nach der Körperkonstitution, der Kleidung und anderen visuellen Angaben ist es eine und dieselbe Figur. Die Positionierung der beiden ermöglicht es, das Geschehen auf dem Papier als eine vollzogene Bewegung zu betrachten: die hintere Figur befindet sich gerade in der Bewegung, durch eine Drehung zum Publikum hin "verwandelt« sie sich in die vordere Figur, diese macht einen Schritt nach vorne und bleibt in der Position sen facer stehen. 1910 fertigte Schiele einige Serien von Selbstakten: „Sitzender männlicher Rückenakt« (in über zehn Variationen, Abb. 10) »Liegender männlicher Akt (ebenso in über zehn Variationen). In diesen Aquarellarbeiten verändert Schiele die Konstellationen der Arme, Beine, die Verrenkungen und Verbiegungen des Körpers in einer solchen Mannigfaltigkeit, dass der Blick des Betrachters nolens volens eine Geschwindigkeit entwickelt, mit der er alle Selbstakte als eine Darbietung absorbiert.

Der monologische Charakter der Arbeiten, die Entlastung des Bildhintergrunds, d.h. der "Bühne" von Requisiten hebt die Materialität des Körpers auf eine ganz besondere Art und Weise hervor. In der pantomimischen Darstellung von Schiele findet sich weder eine Sujetlinie, noch Dramatik, noch ein typisches 'Happy Endk. Es geht hier weniger

35 Simon, Pantomime (wie Anm. 13), S. 72.

Zu den Selbstbildnissen von Egon Schiele 387 


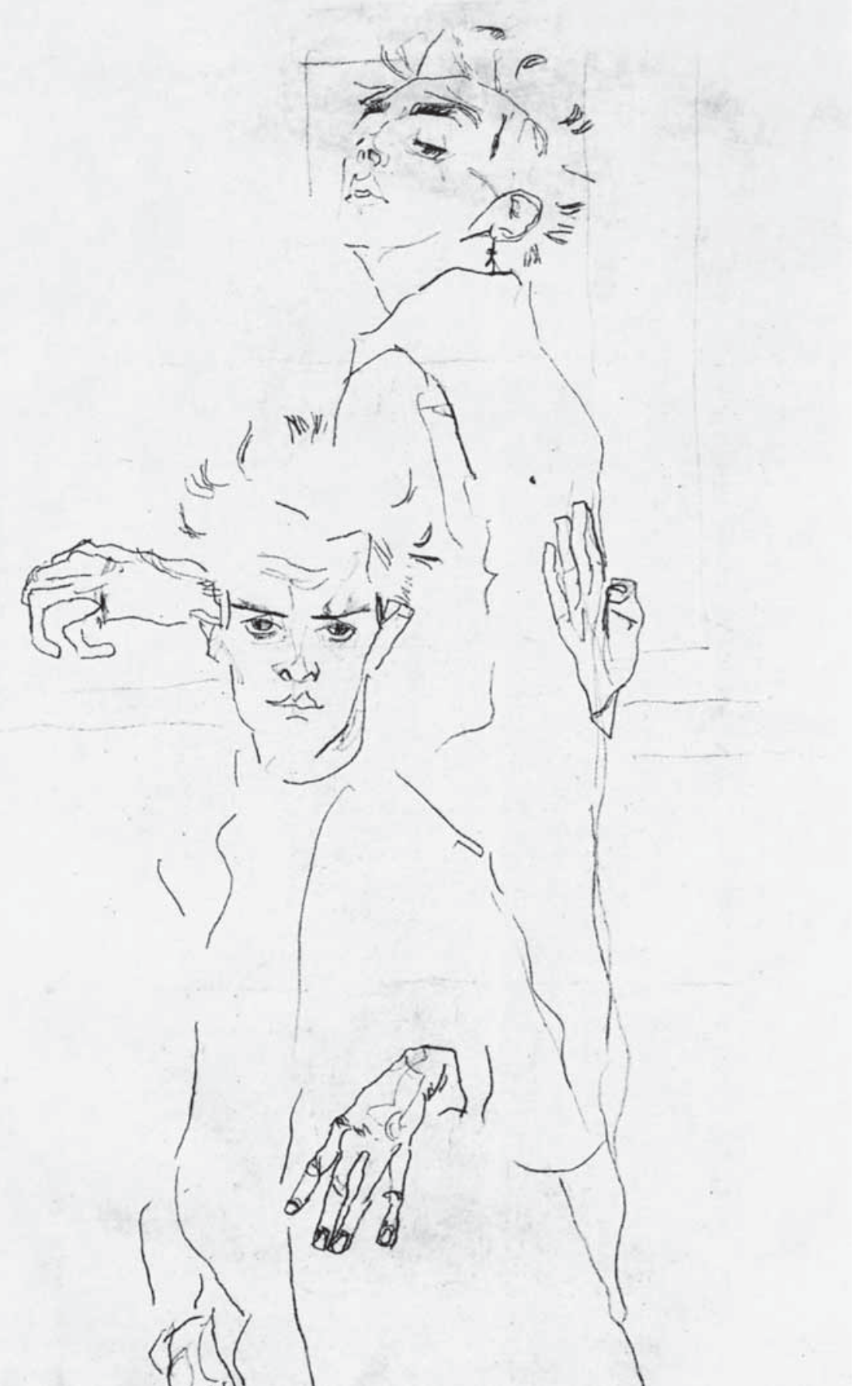

Abb. 9 

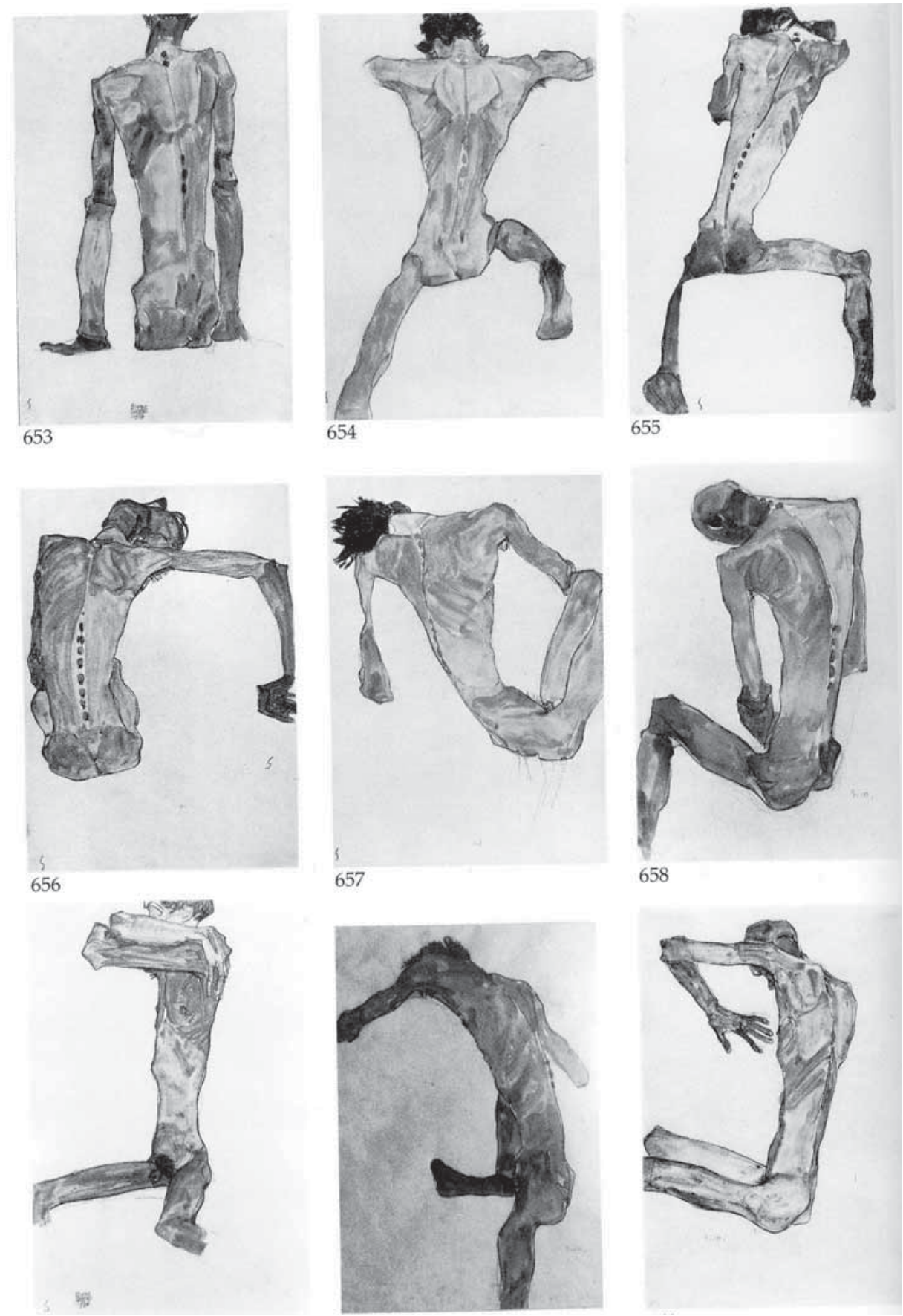

Abb. 10

Zu den Selbstbildnissen von Egon Schiele 389 
um das Verstehen der Handlung als um die körperliche Erfahrung, die sich beim Betrachter einstellt. Abgesehen davon, dass Schieles Figuren interpretatorisches Potenzial anbieten (die am eigenen Leib ausgeübte Gewaltsamkeit, die Figur des Heiligen oder Melancholikers), befreit der Künstler den Körper von der Schwere der Bedeutung und Symbolik, er konzentriert sich auf das Sich-Zeigen. Er agiert als "mime pur« im Sinne von Etienne Decroux: der Akteur verzichtet komplett auf die Ausdrucksfähigkeit des Gesichts, und in der semantischen Zeichendimension produziert er keine Symbole. ${ }^{36}$ Wie in Antonin Artauds »Theater der Grausamkeit" verschiebt sich das Augenmerk von der Bedeutung der Zeichen auf deren Materialität, der Körper des Schauspielers wird wieder zu einem phänomenalen sinnlichen Leib, der sich selbst präsentiert.

Seinen Körper nutzte Schiele auch als Instrument, mit dem er sein Theater schuf.

Bekanntlich besaß er zwei große mobile Standspiegel in seinem Atelier. Die Nutzung der objektivierenden Funktion des Spiegels wird mehrfach in der Schiele-Forschung als Zeichen seiner Eitelkeit und Hinterfragung seines Ichs interpretiert.

Das Posieren vor den Spiegeln trägt eher einen experimentellen Charakter. Hier arbeitete Schiele simultan an seinem eigenen Körper und an der Leinwand, auf die er das Erprobte übertrug. Es ging ihm allein um einen momentanen, im Experiment vor dem Spiegel entstandenen $\mathrm{Zu}$ stand. Das Ergebnis ist Schieles bewusste Selbststilisierung zum Kunstwerk, er erscheint als »sensitiver Selbstentdecker «. ${ }^{37}$

Anschließend sei noch eine interessante Tatsache angemerkt. Vor einigen Jahren durchgeführte Versuche, Schieles Bibliothek zu rekonstruieren, zeigen, dass der Künstler Ausgaben von Arthur Rimbaud, Rainer Maria Rilke, Oskar Kokoschka und etwa den "Almanach des Blauen Reiters" von Wassily Kandinsky und Franz Marc besaß. ${ }^{38}$ Allerdings wird nicht klar, ob er mit den Texten der deutschen Klassiker vertraut war. In diesem Zusammenhang erscheint es bewundernswert, dass sich Schiele das, was man in Goethes »Regeln für Schauspieler« (1803) liest,

36 Vgl. Bollmann, Untersuchungen (wie Anm. 12), S. 47f.

37 Steiner, Egon Schiele 1890-1918 (wie Anm. 31), S. 58.

38 Vgl. Sandra Tretter, »Ich bin Mensch, ich liebe den Tod und ich liebe das Leben«- Egon Schieles »Wortbilder" des Jahres 1910. In: Egon Schiele. Melancholie und Provokation (wie Anm. 31), S. 84. 
für die Ausarbeitung seiner Attitüden und Posen angeeignet hat. Goethe hat scharfsinnig erkannt, wie wichtig die Vorbereitung der pantomimischen Elemente für das Worttheater ist:

Man stelle sich vor einen Spiegel und spreche dasjenige, was man zu deklamieren hat, nur leise oder vielmehr gar nicht, sondern denke sich nur die Worte. Dadurch wird gewonnen, daß man von der Deklamation nicht hingerissen wird, sondern jede falsche Bewegung, welche das Gedachte oder leise Gesagte nicht ausdrückt, leicht bemerken, so wie auch die schönen und richtigen Gebärden auswählen und dem ganzen Gebärdenspiel eine analoge Bewegung mit dem Sinne der Wörter als Gepräge der Kunst aufdrücken kann. ${ }^{39}$

Agnes Husslein-Arco und Alfred Weidinger liefern einen wichtigen Hinweis darauf, dass das Medium des Spiegels und der Photographie die wichtigsten Hilfsmittel für Schieles mimische Studien waren. Die Photographie ersetzte aber den Spiegel ganz besonders 1913 und 1914, als der Künstler den Photographen Josef Trčka kennenlernte. Von ihm ließ er seine expressiven Gesten und Posen selbstbildnishaft mit der Kamera festhalten. Trčka sollte wenig später Tanzposen für Protagonistinnen des freien Ausdruckstanzes schaffen, die für den Wiener Kinetismus eine bedeutende Inspirationsquelle darstellen. Der Photograph sah in Tanz und rhythmischer Gestaltung eine wesentliche Grundlage für ein authentisches, eigenschöpferisches künstlerisches Arbeiten. ${ }^{40}$

39 Johann Wolfgang Goethe, Regeln für Schauspieler. In: Sämtliche Werke, Jubiläumsausgabe in 40 Bde. Hg. von Eduard von der Hellen. Stuttgart, Berlin, Bd. 36 (1902), S. 210.

40 Vgl. Husslein-Arco/Weidinger, Egon Schiele (wie Anm. 24), S. 18-28. 
